Kong. Res. J. 3(1) : 12-14, 2016

Kongunadu Arts and Science College, Coimbatore.

\title{
MICROWAVE ASSISTED SYNTHESIS AND STRUCTURAL CHARACTERIZATION OF NICKEL OXIDE NANOPARTICLES
}

\author{
Kalpanadevi, $\mathrm{K}^{*}$. and R. Manimekalai \\ Department of Chemistry, Kongunadu Arts and Science College, Coimbatore. \\ *E.mail: drkalpanadevik@gmail.com
}

\begin{abstract}
Nickel oxide $(\mathrm{NiO})$ nano-particles were produced via a simple microwave method from the $\mathrm{Ni}(\mathrm{OH})_{2}$ precursor, which was obtained by slow drop-wise addition of $0.1 \mathrm{M}$ sodium hydroxide to $0.1 \mathrm{M}$ nickel nitrate. The mixture was vigorously stirred until the $\mathrm{pH}$ reached 7.2. The mixture was then irradiated with microwave to deposit $\mathrm{Ni}(\mathrm{OH})_{2}$ at a better precipitation rate. Drying the precipitate at $320^{\circ} \mathrm{C}$ resulted in formation of NiO nanoparticles. High Resolution Transmission Electron Microscope (HRTEM), Scanning Electron Microscope (SEM) and X-ray diffraction (XRD), employed for the structural characterization of the as-prepared $\mathrm{NiO}$ nanoparticles, revealed their good crystallinity and high-purity. Microwave irradiation increased homogeneity and decreased the mean particle size of the produced NiO particles.
\end{abstract}

Keywords: NiO, microwave synthesis, nanoparticles, HRTEM, SEM, XRD.

\section{INTRODUCTION}

Nano-particle oxides of transition metals have attracted materials scientists. These materials have exceptional properties which stimulate many advanced applications (Duran et al., 2003; Wang et al., 2005 Mazaheri et al., 2008). Nano-structured nickel oxide is a prominent example having a large exciton binding energy and a wide band gap ranging from 3.6 to $4.0 \mathrm{eV} .4,5$ This p-type semiconductor can be used in optical, electronic, catalytic and superparamagnetic devices like transparent conductor films, gas sensors, alkaline battery cathodes, dyesensitized solar cells and solid oxide fuel cells (SOFC) (Bhadur et al., 2008; Sato et al., 1993). Versatile methods such as sol-gel (Ghosh et al., 2006; Wu et al., 2007), chemical precipitation (Bhadur et al., 2008; Bahari Molla Mahaleh et al., 2008) and anodic arc plasma method (AAPM) (Hongxia et al., 2009) have been used to produce nanomaterials. Microwave heating has such advantages as highefficiency, nanoparticle rapid-formation, narrow crystallite size distribution and agglomeration decrease when compared to the conventional methods (Krishnakumar et al., 2009). Microwave methods apply electromagnetic waves having 0.001 to $1 \mathrm{~m}$ wavelength to accelerate the chemical reaction of interest. These wavelengths correspond to frequencies between 0.3 to $300 \mathrm{GHz}$. Synthesis via microwave routes is simple, energy efficient, time saving and produce great of samples (Krishnakumar et al., 2009). Production of nickel oxide nanoparticles by microwave chemical synthesis, their morphological characterization and their structural study are discussed in this paper.

\section{MATERIALS AND METHODS}

\subsection{Preparation of NiO nanoparticles}

Microwave synthesis of $\mathrm{NiO}$ nanoparticles comprised three stages: (1) formation of $\mathrm{Ni}(\mathrm{OH})_{2}$ precursor, (2) microwave irradiation of $\mathrm{Ni}(\mathrm{OH})_{2}$ and (3) annealing of $\mathrm{Ni}(\mathrm{OH})_{2}$ to convert into $\mathrm{NiO} . \mathrm{Ni}(\mathrm{OH})_{2}$ precursor was obtained by drop-wise slow addition of $0.1 \mathrm{M} \mathrm{NaOH}$ to $0.1 \mathrm{M} \mathrm{Ni}\left(\mathrm{NO}_{3}\right)_{2}$ while vigorous stirring of the solution continued until the $\mathrm{pH}$ reached 7.2. The mixture was then irradiated by microwave $(2.45 \mathrm{GHz}, 900 \mathrm{~W}$, SAMSUNG) until a dry green precipitate formed. Simultaneous thermal analysis (TG-DTA) was carried out using (Universal V4.5A TA Instrument) to determine the $\mathrm{Ni}(\mathrm{OHs})_{2}$ to $\mathrm{NiO}$ conversion temperature under air. After determining the temperature of nickel hydroxide to nickel oxide conversion by thermal analysis, the oven-dried cake was heated up to $320^{\circ} \mathrm{C}$ for 1 hour to form dark grey particles. The resulting powder was filtered and washed several times with distilled water and finally with ethanol to remove the residual by products.

\subsection{Characterization of the prepared nanoparticles}

X-ray diffraction (X'per PRO model) was used for structural study and characterization of the sample. Phase purity of the initial powder was also investigated by XRD. Morphological study was carried out by Scanning Electron Microscope (HITACHI Model S-3000H). High Resolution 
Transmission Electron Microscope (Jeol Gem Model) was used to analyse the particle size of the $\mathrm{NiO}$ nanoparticles.

\section{RESULTS AND DISCUSSION}

\subsection{Thermal Analysis}

Fig. 1 shows TG-DTA curves of the $\mathrm{Ni}(\mathrm{OH})_{2}$ precursor. It can be seen that two endothermic reactions take place between ambient temperature and $600^{\circ} \mathrm{C}$ in the sample $\mathrm{Ni}(\mathrm{OH})_{2}$. Both reactions accompanied the mass reduction due to $\mathrm{H}_{2} \mathrm{O}$ removal from the powder, to form $\mathrm{NiO}$ as the end product (Kim et al., 2006).



Fig. 1. TG-DTA Curves of $\mathrm{Ni}(\mathrm{OH})_{2}$

\subsection{XRD analysis}

XRD pattern (Fig. 2) confirms the formation of nickel oxide (JCPDS card No. 22-1189). No other components were detectable in the final product. The mean crystallite size was calculated by application of the Debye-Scherer equation, $D=K \lambda / \beta$ $\cos \theta$, where, $\theta$ is Bragg diffraction angle, $\mathrm{K}$ is Blank's constant, $\lambda$ is the source wavelength (1.54), and $\beta$ is the width of the XRD peak at half maximum height, is $19 \mathrm{~nm}$ (Needham et al., 2006).

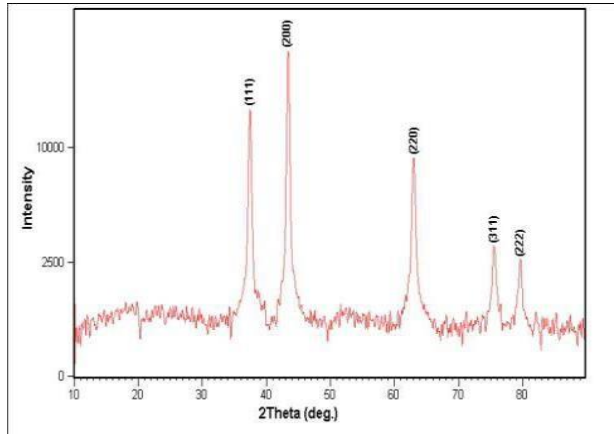

Fig. 2. XRD pattern of NiO nanoparticles

\subsection{SEM Analysis}

Aggregated particles around 50 to $300 \mathrm{~nm}$ in diameter are observable in the SEM images (Fig. 3).
Their creation may be due to the influence of the interfacial energies and intraparticle magnetic interactions.

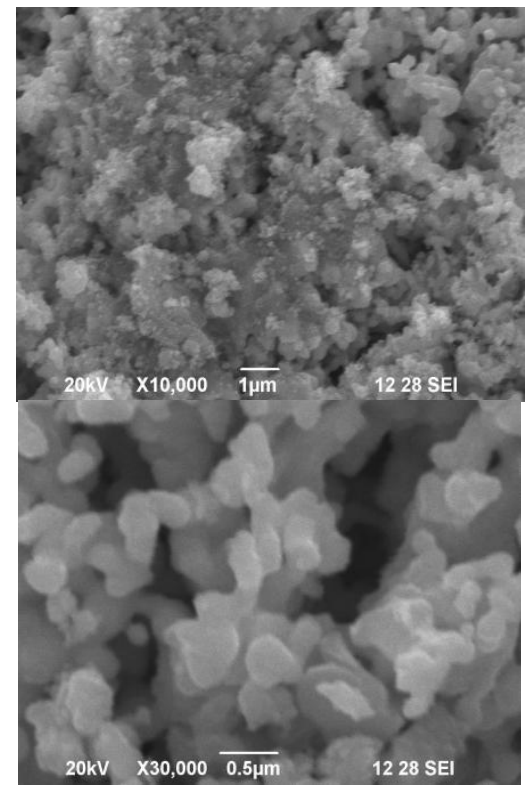

Fig. 3. SEM images of NiO nanoparticles

\subsection{HRTEM Analysis}

HRTEM images are shown in Fig. 4. They exhibit $\mathrm{NiO}$ nanoparticles having mean crystallite size of $\sim 20 \mathrm{~nm}$.

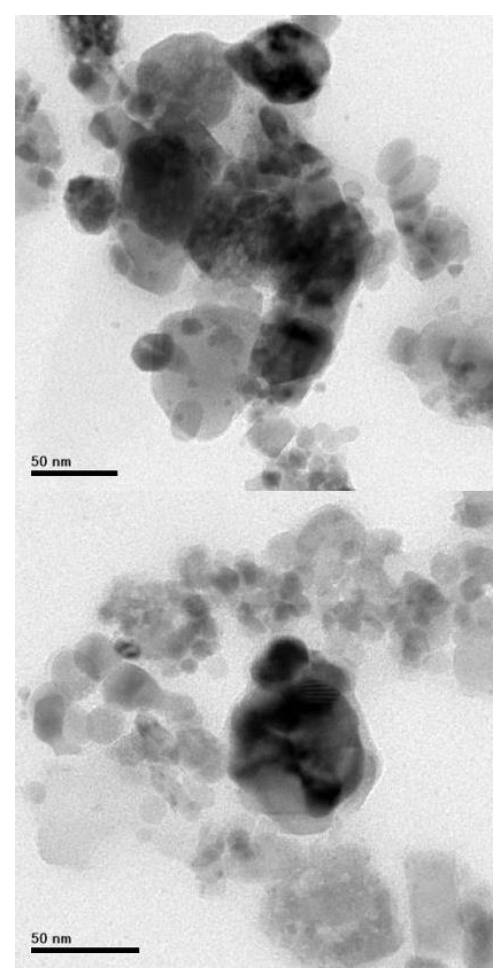

Fig. 4. HRTEM images of NiO nanoparticles 


\section{CONCLUSION}

Highly-crystallized pure nickel oxide nanoparticles with a mean crystallite size of around $20 \mathrm{~nm}$ were synthesized by a microwave chemical approach. Morphology of the produced sample showed wellshaped homogenously crystallized particles. Microwave irradiation has been found to be efficient in speeding up of the production rate and reduction of the size of particles.

\section{REFERENCES}

Bahadur, J., D. Sen, S. Mazumder and S. Ramanathan, (2008). Effect of heat treatment on pore structure in nano-crystalline NiO: A small angle neutron scattering study. J. Sol. Sta. Chem., 181:1227-1235.

Bahari Molla Mahaleh, Y., S.K. Sadrnezhaad and D. Hosseini. (2008). NiO Nanoparticles Synthesis by Chemical Precipitation and Effect of Applied Surfactant on Distribution of Particle Size. J. Nanomat., 2008: 1-4.

Duran, P., J. Tartaj and C. Moure, (2003). Fully Dense, Fine-Grained, Doped Zinc Oxide Varistors with Improved Nonlinear Properties by Thermal Processing Optimization. J. Am. Ceram. Soc., 86: 1326-1329.

Ghosh, M., K. Biswas, A. Sundaresan and C.N.R. Rao, (2006). MnO and NiO nanoparticles: synthesis and magnetic properties. J. Mat. Chem., 16: 106111.

Hongxia, Q., W. Zhiqiang, Y. Hua, Z. Lin and Y. Xiaoyan, (2009). Preparation and Characterization of $\mathrm{NiO}$ Nanoparticles by Anodic Arc Plasma Method. J. Nanomat., 2009: 1-5.
Kim, S.S., K.W. Park, J.H. Yum and Y.E. Sung, (2006). $\mathrm{Pt}-\mathrm{NiO}$ nanophase electrodes for dye-sensitized solar cells. Sol. Energy Mater. Sol. Cells, 90: 283290.

Krishnakumar, T., R. Jayaprakash, N. Pinna, V.N. Singh, B.R. Mehta and A.R. Phani, (2009). Microwave-assisted synthesis and characterization of flower shaped zinc oxide nanostructures. Materials Letters, 63: 242-245.

Mazaheri, M., A.M. Zahedi and M.M. Hejazi, (2008). Processing of nanocrystalline $8 \mathrm{~mol} \%$ yttriastabilized zirconia by conventional, microwaveassisted and two-step sintering. Mater. Sci. Eng. A, 492: 261-267.

Needham, S.A., G.X. Wang and H.K. Liu, (2006). Synthesis of $\mathrm{NiO}$ nanotubes for use as negative electrodes in lithium ion batteries. J. Power Sources, 159: 254-257.

Sato, H., T. Minami, S. Takata and T. Yamada, (1993). Transparent conducting p-type NiO thin films prepared by magnetron sputtering. Thin Solid Films, 236: 27-31.

Wang, J. and L. Gao, (2005). Photoluminescence Properties of Nanocrystalline ZnO Ceramics Prepared by Pressureless Sintering and Spark Plasma Sintering, J. Am. Ceram. Soc., 88: 16371639.

Wu, Y., Y. He, T. Wu, T. Chen, W. Weng and H. Wan, (2007). Influence of some parameters on the synthesis of nanosized $\mathrm{NiO}$ material by modified sol-gel method. Materials Letters, 61: 3174-3178. 